\title{
Cemented paste backfill response to isotropic compression
}

\author{
Murray Grabinsky \& Mohammadamin Jafari \\ University of Toronto, Toronto, Canada
}

SUMMARY: CPB pressures up to $3.3 \mathrm{MPa}$ have been measured arising from rock closure on the backfill. However, backfill has never been tested at pressures this high and therefore its response to high stress needs investigating. A high-pressure compression test device is described. Test results are presented for isotropic compression tests up to $6.5 \mathrm{MPa}$. The key parameters defining compression response are related to quality UCS test results. The general behaviour is very stable and extrapolating the results to several times the pressures used seems feasible, indicating CPB's suitability for deep and high stress mining.

Keywords: wall closure, backfill pressure, isotropic compression testing

\section{INTRODUCTION}

Backfill is the only form of regional ground support, and its use in deep and high stress mining is essential to maintain host rock stability and limit stress redistributions associated with ongoing mining that could otherwise lead to concentrated stresses and dangerous rockbursting conditions. Thompson et al. (2011) show field stress monitoring results from Kidd mine where initial stresses of a few hundred $\mathrm{kPa}$ jump to over $800 \mathrm{kPa}$ with continued mining, and to over $1 \mathrm{MPa}$ resulting from a $\mathrm{Mn} 3.8$ rockburst that occurred a few hundred meters from the monitored stope. Subsequent work at Kidd mine employed higher capacity stress cells (Counter, 2014), and ultimately stresses in excess of 3.3 $\mathrm{MPa}$ were recorded using cells with $10 \mathrm{MPa}$ capacity ${ }^{1}$. Although testing under these kinds of stresses is relatively common for rock materials, it is unheard of for backfills. The purpose of this work is therefore to generate new data in order to better understand CPB's response to isotropic compression under high stress regimes. The isotropic stress path is also fundamentally important to calibrating constitutive models where pressure stress is one of the stress invariants and yielding and hardening along this path forms an essential part of a more general "cap" that then describes the material's volumetric response to loading.

Isotropic compression testing is a comparatively rare test technique for any geotechnical material. Jafari (2019) provides a review of test results for naturally and artificially cemented soils. Naturally cemented soils have been tested by Airey (1993), Burland (1990), Cuccovillo and Coop (1999), Cuccovillo and Coop (1997). Artificially cemented soils have been tested by Arroyo et al. (2013), Clough et al. (1989), Coop and Atkinson (1993), Horpibulsuk et al. (2004), Huang and Airey (1998), Lo and Wardani (2002), Malandraki and Toll (2000), Malandraki and Toll (2001), Miura et al. (2001), Rios et al. (2012), Rotta et al. (2003), Santos et al. (2010), Xiao et al. (2014), and Xiao and Lee (2014).

1. Personal communications with D. Counter, November 6, 2019

DOI: $10.1201 / 9781003205906-12$ 
In general, it is understood that the cement bonds create a structure within the solid particle's network. In isotropic compression loading, this will enhance the initial yield strength as compared to the uncemented material. The distinction between weak bonds and strong ones is based on the location of the intrinsic isotropic normal compression line in specific volume versus logpressure space (Figure 1): for weakly cemented materials the bonds crush relatively quickly and the material soon returns to its unstructured state and behaves accordingly at large compressive stresses; for strongly cemented materials the initial nearly-linear response extends beyond the intrinsic isotropic normal compression line and much higher stress is required to degrade the bond structure and accelerate volume change with increasing stress (point $\mathrm{s}$ in Figure 1).

Exactly how CPB responds in this volume-stress space has yet to be determined. To investigate this, and to assess whether the material response corresponds to "weakly" or "strongly" cemented for the generally used binder contents (addressed subsequently) a new device had to be constructed. The device is considered first. Then the tested materials are described, and sample test results are shown and discussed within the above framework. Implications for practical mine design are then considered.

\section{ISOTROPIC COMPRESSION TEST DEVICE}

Samples were prepared to replicate the bulk properties determined from field testing (Grabinsky et al., 2013, 2014). A custom split mold (Figure 2) allows the material to be placed and cured under water for 24 hours, then removed without damaging the specimen when it is then returned to continue curing under water until testing. This avoids oxidation of sulfur-bearing minerals. The final sample's properties are homogeneous. The ends are polished on glass just before testing to remove surface irregularities where paste extruded into the top cap's vents.

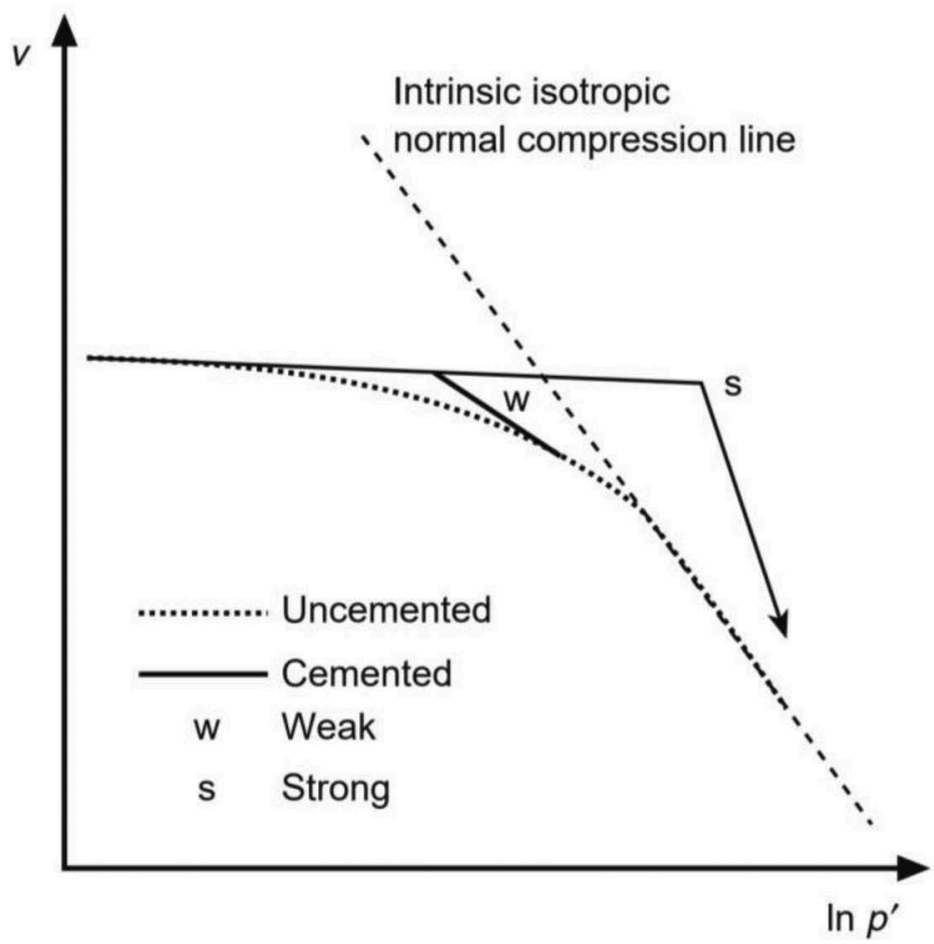

Figure 1. Schematic comparison of the isotropic compression of weakly and strongly cemented carbonate sand (after Cuccovillo and Coop (1999)). 

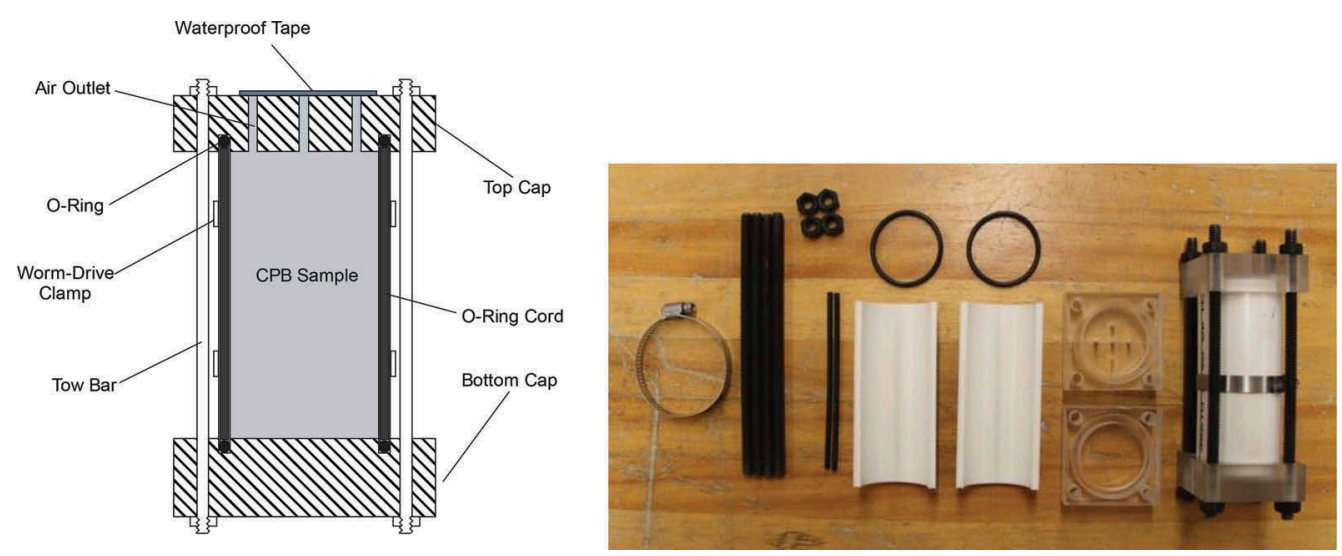

Figure 2. Sample split mold. left: schematic; right: accessories.

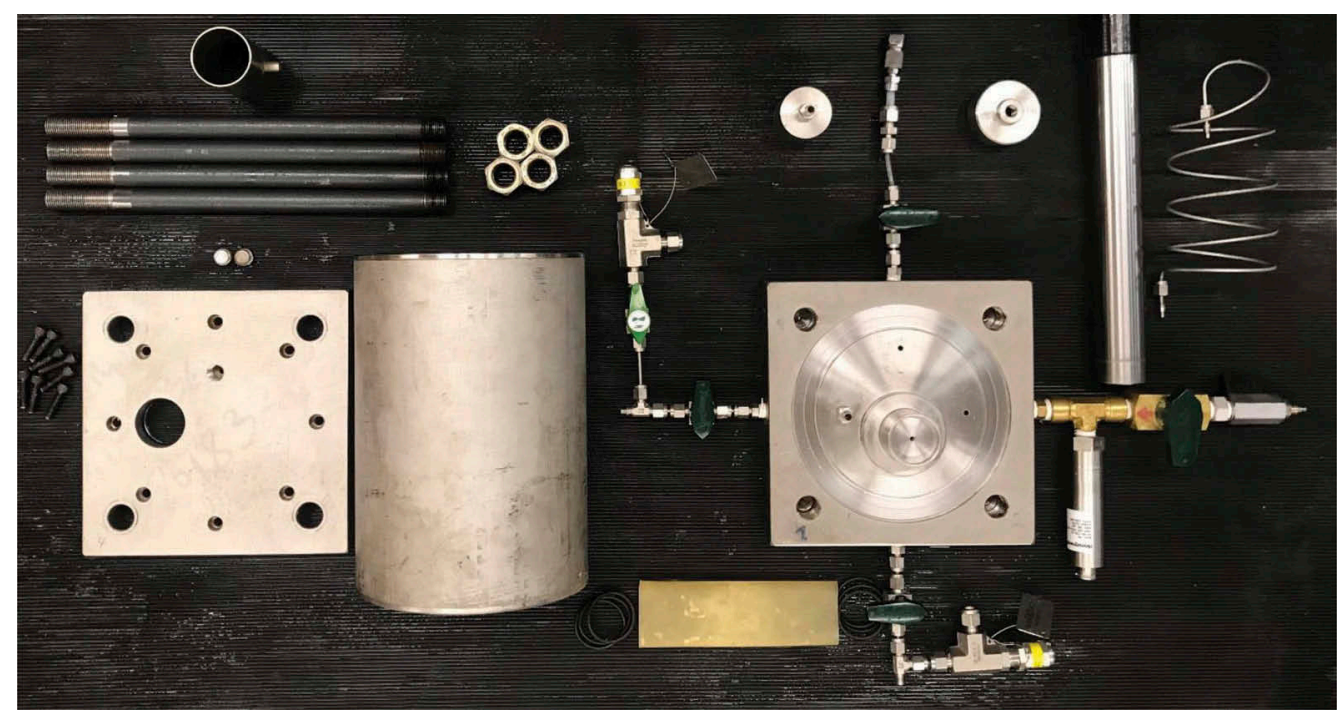

Figure 3. High-pressure isotropic compression cell components.

A cell was designed to test under isotropic compression at pressures up to $20 \mathrm{MPa}$ (Figure 3), although the results shown here will be limited to $6.5 \mathrm{MPa}$ range. Cell pressure was controlled according to feedback from a pressure transducer with $1000 \mathrm{kPa}$ limits for cell pressure less than $1 \mathrm{MPa}$, and a pressure transducer with $20 \mathrm{MPa}$ limits for cell pressure higher than $1 \mathrm{MPa}$. The combination of these sensors enhanced cell pressure accuracy in the high range of pressure. Two electrical pressure transducers with $1000 \mathrm{kPa}$ limits were installed at the top and bottom of the specimen to measure pore water pressure at both ends of the specimen. Also, a frictionless rolling diaphragm type volume change device (VCD) with $0.01 \mathrm{ml}$ resolution was used to measure the volumetric change of specimens. All sensors were calibrated before testing, and the calibration factors for each sensor were frequently checked during the testing program.

Care must be taken to check for apparatus compliances when such high pressures are used. It was found that two of the most significant sources of error when determining volume changes are 1) compliance of the porous disks and filter papers at each of the specimen's ends, and 2) membrane compliance. Methods for correcting these errors are addressed in Jafari et al. (2019).

Later in this work the isotropic compression test results will be compared with UCS results. It should be mentioned that although UCS testing is one of the (apparently) easiest strength 
tests to carry out, there are numerous details that must require attention if the results are to be reliable. If mining operations carry out routine UCS testing as part of a larger QA/QC protocol and find large scatter in the UCS results, then more attention to detail could well resolve many of the apparent testing issues. In particular, all of the UCS tests in this work were carried out under water and at an empirically determined loading rate found low enough not to introduce rate effects. If the testing is done at ambient laboratory atmospheric conditions, and if the loading rate is too high, then suctions can be induced by either the self-desiccation effect associated with hydration (Simms and Grabinsky, 2009), and/or pore pressure changes can be associated with sample contraction (at low strains) or dilation (at large strains), or the water pressures within the sample will not be uniform. To illustrate the effect of testing under water, Figure 4 shows test results for 3\% and one-day cure time uniaxial tests, 3 tests under submerged conditions and 3 tests at ambient (unsubmerged) conditions. The three submerged test results are consistent and indicate a UCS just less than $30 \mathrm{kPa}$, where as the three unsubmerged tests all show significant strain hardening beyond $30 \mathrm{kPa}$ and peak stresses up to four times the actual UCS. These additional apparent "strengths" are due to post-peak sample dilation and induced suctions, which actually increase the effective stress within the sample and lead to apparent strength when interpreted in a total stress context.

To further demonstrate that the apparent strengths in Figure 4 for unsubmerged tests are not real, Figure 5 shows uniaxial tests on $7.5 \%$ binder content and 3-day cure time specimens, all in unsubmerged conditions, for which apparent stresses are artificially high. The third sample was loaded to a level similar to the failure condition for the first two samples, and then water was splashed on the sample's exposed surfaces. This water was absorbed into the sample and reduced the suctions, thereby reducing the effective stress within the sample and so reducing the sample's load-bearing capacity. Over a few seconds the sample loses loadbearing capacity and ultimately fails. (The sample is tested in a displacement-controlled frame, so when the initial testing stops and water is splashed onto the sample, the displacement does not change but the reduction in load is registered by the frame's load cell.)

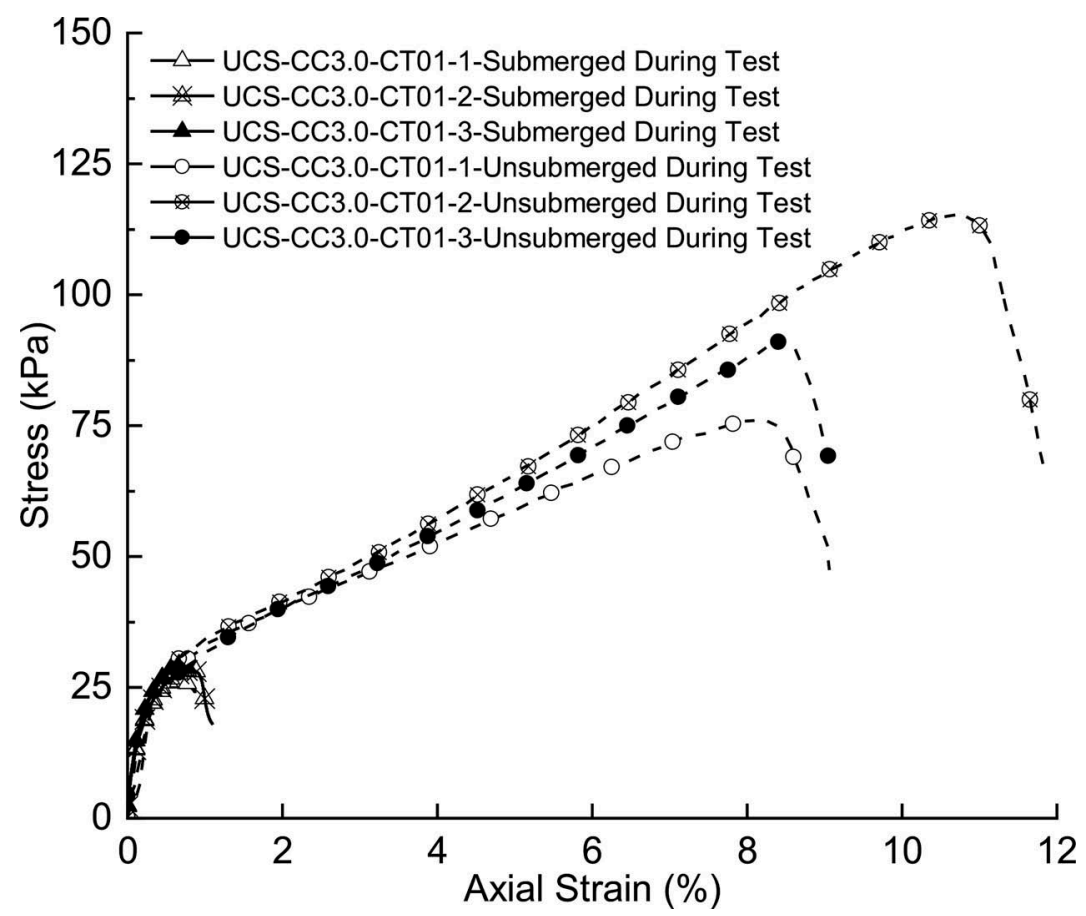

Figure 4. Uniaxial test results under submerged and unsubmerged testing conditions. 


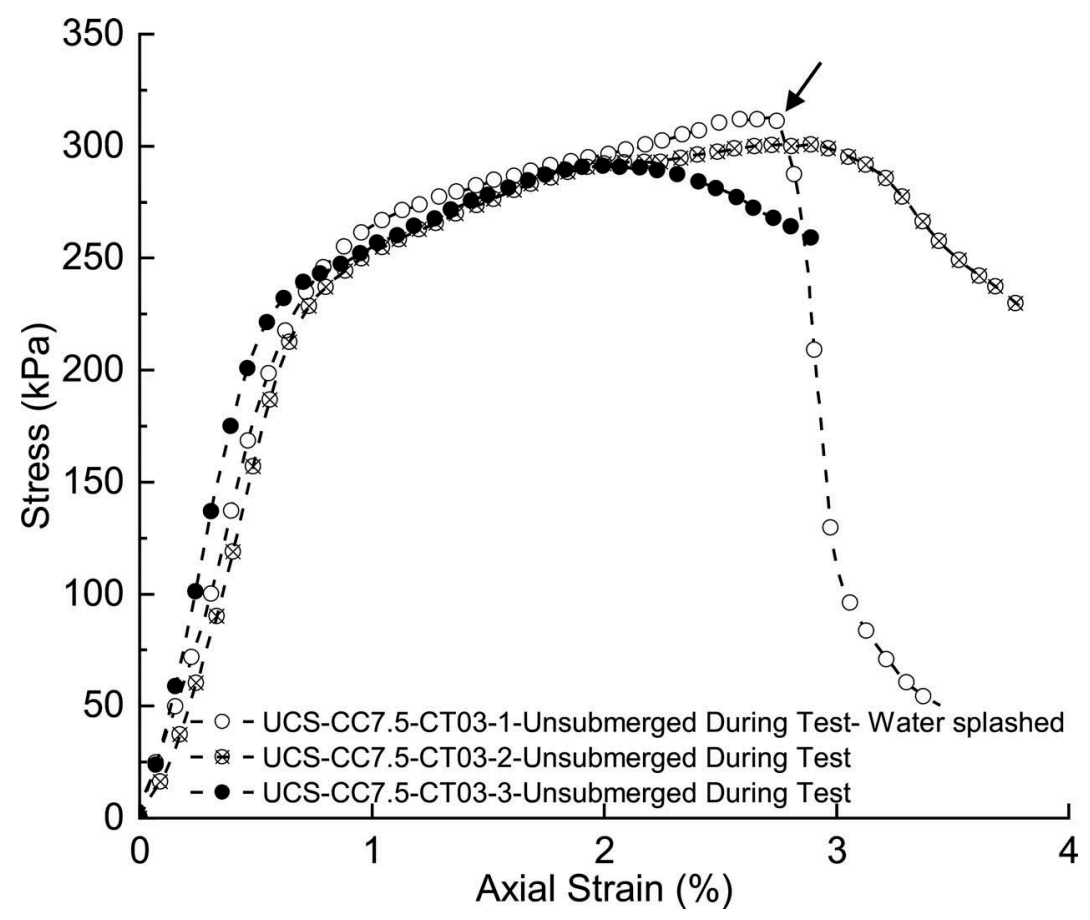

Figure 5. UCS tests with dilation-induced suction, and the effect of splashing water on the exposed surfaces of one of these specimens (at location of arrow).

\section{MATERIALS TESTED}

The CPB materials come from Barrick Gold Corp's Williams mine near Marathon, Ontario (Canada). The tailings are classified as non-plastic silt with $40 \%$ passing $0.020 \mathrm{~mm}$ which satisfies one of the generally accepted criteria for paste (minimum $15 \%$ passing $0.020 \mathrm{~mm}$ ). Binder contents between $3 \%$ and $11.1 \%$ were tested because these correspond to the minimum and maximum generally used at the mine, depending on the detailed mine design scenario. Water content is consistent at $38 \%$ on a mass of water divided by mass of solids (tailings + binder) basis (the common definition used in geotechnical engineering), which is equivalent to $27.5 \%$ on a mass of water divided by total mass basis (the common definition used in backfill design). Tests were also carried out at varying cure times up to 28 days to better understand how the properties and behavior evolve with different hydration stages, however only the 28day results will be presented here. The tailings contain relatively low amounts of sulfurbearing minerals compared to other gold mines (in Canada in particular) and probably as a result do not suffer from long term strength degradation.

\section{SAMPLE TEST RESULTS}

Results are presented here for 3\% and $11.1 \%$ binder content, at 1-day to 28-day cure times (Figures 6 and 7).

The 1-day cure times are thought to correspond to the "weakly cemented" material response characterized in Section 1, whereas at 3-day cure and longer the material strength increases and the "strongly cemented" material response is enhanced. For each test the initial response was linear and therefore the bulk modulus could be determined, and the onset of nonlinearity, $\mathrm{YS}_{\mathrm{ISO}}$, was readily identified (Figure 8 ) and this value was found to be only marginally larger (by about 7\%) than the corresponding onset of nonlinearity from the UCS tests. 


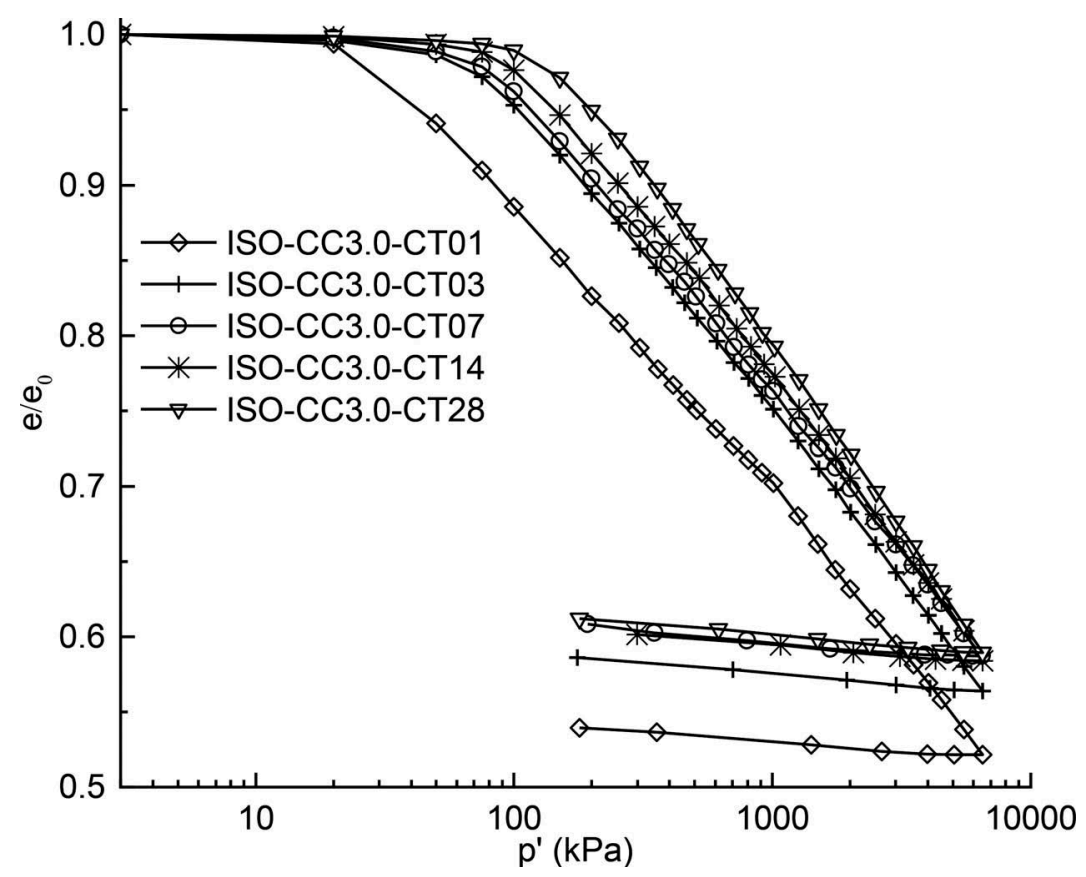

Figure 6. Isotropic compression test results for 3\% binder content, 1-day to 28-day cure times.

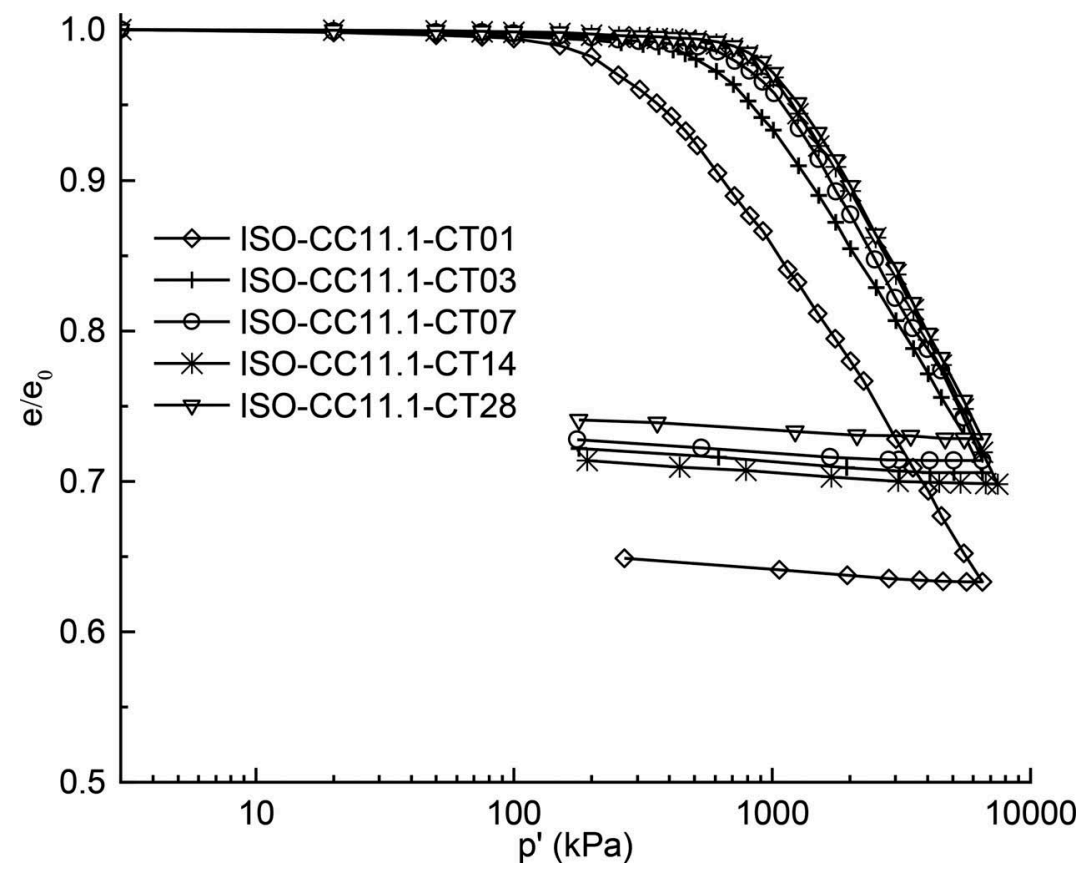

Figure 7. Isotropic compression test results for $11.1 \%$ binder content, 1-day to 28 -day cure times.

The overall response of each isotropic compression test can be generalized as shown for a particular test result in Figure 9. Initial loading (starting at A) is linear up to $\mathrm{YS}_{\text {ISO }}$ (point B) and deformation is controlled by the bulk modulus. Beyond $\mathrm{YS}_{\mathrm{ISO}}$ the nonlinear response increases and approaches a new tangent (point $\mathrm{C}$ ) to a new linear response characterized as the 


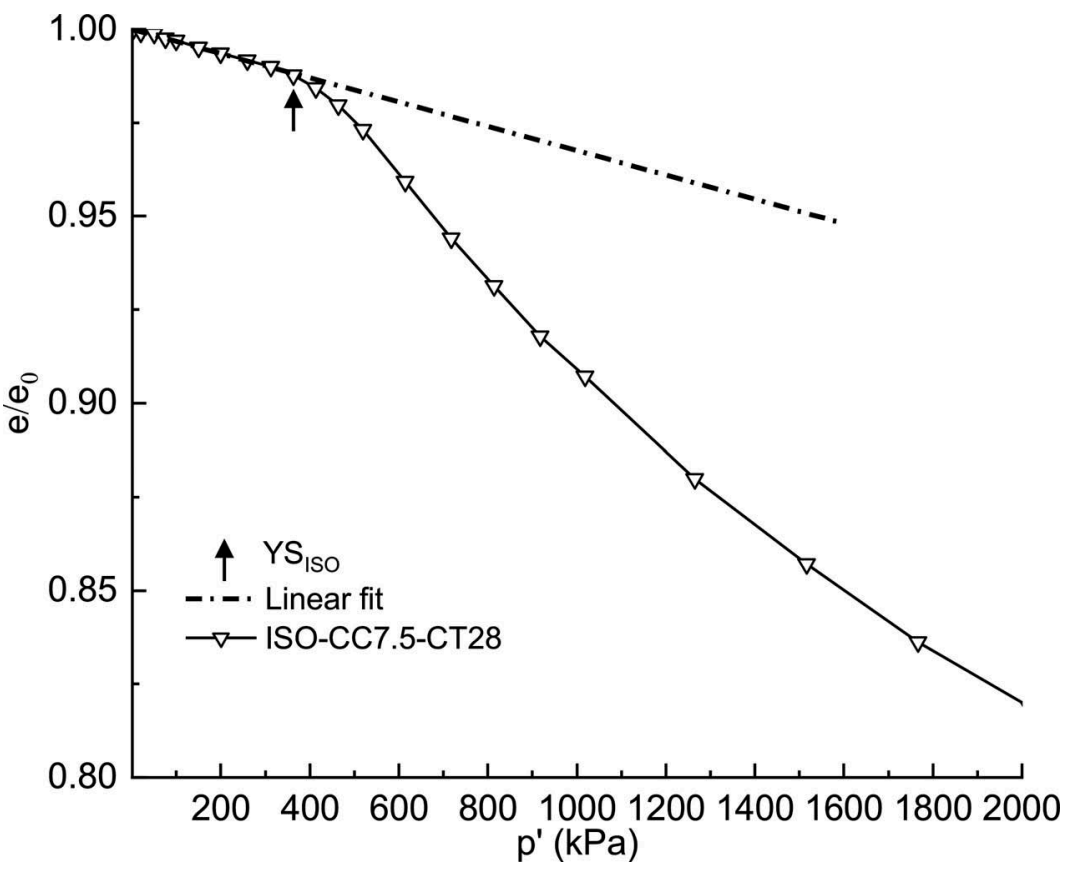

Figure 8. Identification of initial non-linearity $\left(\mathrm{YS}_{\mathrm{ISO}}\right)$ in isotropic compression.

Post-yield Compression Line ( $\mathrm{C}$ to $\mathrm{D}$ ). Upon unloading (point $\mathrm{D}$ ) the response is again almost linear with slope very similar (in log space) to the initial bulk modulus (A to B). Note that the overall response has many similarities to the one-dimensional compression (oedometer) results for overconsolidated clays.

The initial tangent for bulk modulus (line A to B) intersects with the Post-yield Compression Line at a point $P_{\text {ISO }}$ in void ratio - log-pressure space (Figure 9). For all of the test results, over the range $3 \%$ to $11.1 \%$ binder content and 1-day to 28-day cure times, Jafari (2019) found that $\mathrm{P}_{\text {ISO }}=1.14$ UCS. Therefore, both $\mathrm{YS}_{\text {ISO }}$ and $\mathrm{P}_{\text {ISO }}$ can be strongly correlated to high-quality UCS test results, which is extremely useful when conducting parametric analyses to examine the design implications of intermediate binder contents.

Finally, it is instructive to consider extrapolating the available test results into higher compression ranges. If the 1-day test results at high stress is indicative of an "uncemented" response (i.e., all bonds destroyed) and thus used as a tangent for the inherent material's Postyield Compression Line; and if in the same lower void ratio range the trend of the Post-yield Compression Lines is examined to estimate the tangent to the 28-day curve; then extrapolating these two tangents to lower void ratios and their intersection point, one finds a pressure stress approaching $100 \mathrm{MPa}$ at void ratios around 0.3 . While this approach is admittedly speculative, it is interesting that these values ( $100 \mathrm{MPa}$ at 0.3 void ratio) would still lie completely in the plausible range for stable backfill remaining within the contained void space. As such, the backfill would continue to provide extremely effective regional ground support even under the most extreme loading conditions.

\section{CONCLUSIONS AND IMPLICATIONS FOR PRACTICAL MINE DESIGN}

More complete background, test results, and interpretations can be found in Jafari (2019) and these are also currently in peer review for anticipated journal publication. In the current article the isotropic test device has briefly been described, and the importance of high-quality UCS testing and straightforward steps that can be taken to achieve good results have been 


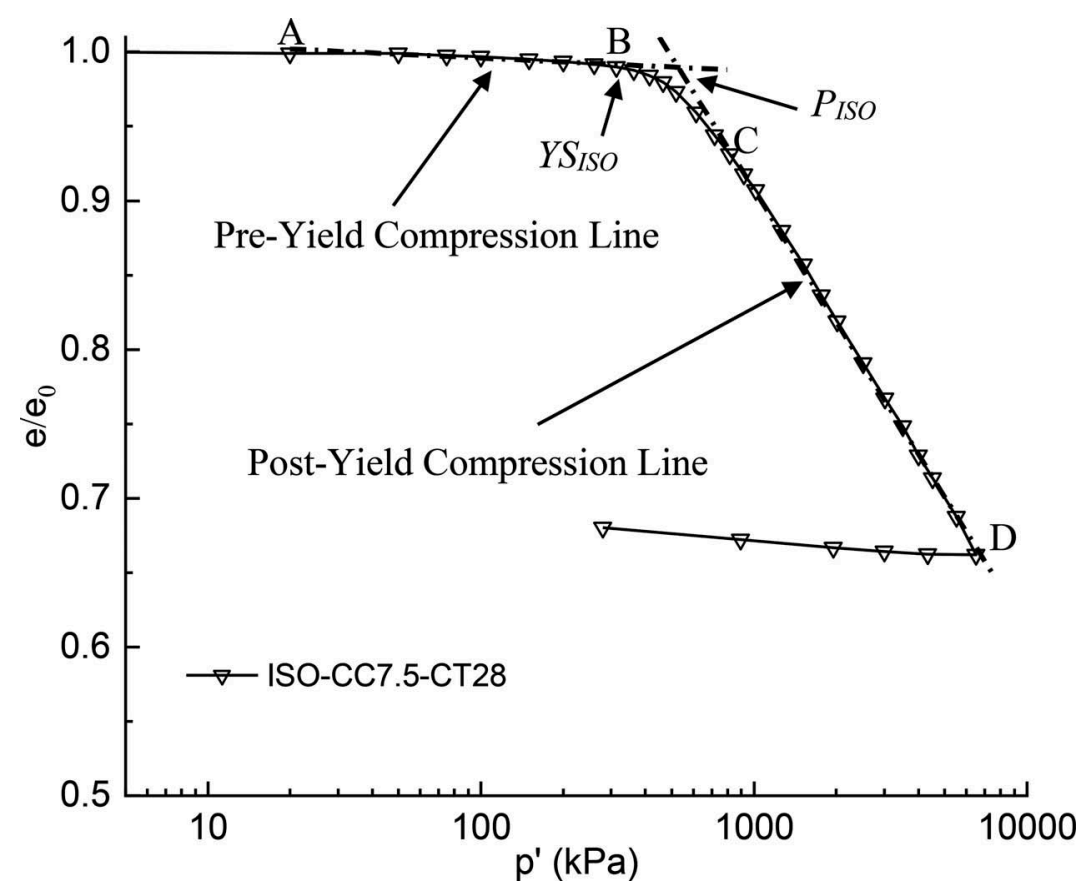

Figure 9. General characterization of response to isotropic compression.

highlighted. Even the bounding test results, shown for $3 \%$ and $11.1 \%$ binder contents, offer the first glimpse into the properties and behavior of CPB under multiple-MPa range isotropic compressive stresses.

The high-quality UCS test results available in this work allowed strong correlations between properties in isotropic compression loading and uniaxial loading. In particular, the onset of nonlinearity in isotropic compression was only marginally higher (factor 1.07) than the corresponding onset of nonlinearity in UCS tests. As well, the characteristic point for transitioning from initial elastic behavior (controlled by bulk modulus) to Post-Yield Compression behavior, $\mathrm{P}_{\mathrm{ISO}}$, was strongly correlated to UCS (factor 1.14). These correlations allow for parametric analysis where intermediate values of binder content and cure time might be considered for specific mine design scenarios.

The admittedly speculative extrapolation of available test results to their assumed "critical end point" suggests the tested backfill could stably sustain a $100 \mathrm{MPa}$ isotropic stress at a void ratio around 0.3 , at which point the backfill would likely be transformed into a something similar to siltstone.

More importantly, the test techniques and testing framework provide an approach that can be used to test other mine's CPB materials to determine if similar, or other correlations can be derived. Further such testing will lead to a much fuller understanding of CPB's effectiveness in providing regional ground support under the most extreme loading conditions.

\section{ACKNOWLEDGEMENTS}

This work was financially supported by Barrick Gold Corp and the Natural Sciences and Engineering Research Council Canada (NSERC) through a Collaborative Development and Research Grant to the first author. 


\section{BIBLIOGRAPHY}

Airey, D. W. 1993. Triaxial Testing of Naturally Cemented Carbonate Soil. Journal of Geotechnical Engineering 119(9):1379-1398.

Arroyo, M., Amaral, M. F., Romero, E. \& Fonseca, A. V. D. 2013. Isotropic yielding of unsaturated cemented silty sand. Canadian Geotechnical Journal 50: 807+.

Burland, J. B. 1990. On the compressibility and shear strength of natural clays. Géotechnique 40(3):329-378.

Consoli, N. C., Casagrande, M. D. \& Coop, M. R. 2005. Effect of Fiber Reinforcement on the Isotropic Compression Behaviour of a Sand. Journal of Geotechnical and Geoenvironmental Engineering 131(11):1434-1436.

Consoli, N. C., Rotta, G. V. \& Prietto, P. D. M. 2006. Yielding-compressibility-strength relationship for an artificially cemented soil cured under stress. Géotechnique 56(1):69-72.

Coop, M. R. \& Atkinson, J. H. 1993. The mechanics of cemented carbonate sands. Géotechnique 43 (1):53-67.

Counter, D. B. 2014. Kidd Mine-dealing with the issues of deep and high stress mining-past, present and future. In DeepMining 2014-Proc. Of the 7th Int. Conf. on Deep and High Stress Mining (pp. 16-18).

Grabinsky, M. W., Bawden, W. F., Simon, D., Thompson, B. T., \& Veenstra, R. L. 2013. In situ properties of cemented paste backfill from three mines. Proceedings of the 2013 Canadian Geotechnical Conference, GeoMontreal 2013. Montreal. Canadian Geotechnical Society.

Grabinsky, M. W., Simon, D., Thompson, B. D., Bawden, W. F., \& Veenstra, R. L. 2014. Interpretation of as-placed cemented paste backfill properties from three mines. MineFill 2014 (pp. 351-364). Perth: Australian Centre for Geomechanics

Horpibulsuk, S., Bergado, D. T. \& Lorenzo, G. A. 2004. Compressibility of cement-admixed clays at high water content. Géotechnique 54(2):151-154.

Huang, J. T. \& Airey, D. W. 1998. Properties of Artificially Cemented Carbonate Sand. Journal of Geotechnical and Geoenvironmental Engineering 124(6):492-499.

Jafari, M. 2019. Experimental study on physical and mechanical properties of cemented tailings. $\mathrm{PhD}$ Thesis, University of Toronto

Jafari, M., Shahsavari, M. \& Grabinsky, M. 2019. Volumetric change measurement for Cemented Paste Backfill under high isotropic compression: laboratory challenges and tips. In Proceedings of the Canadian Geotechnical Conference Geo St John's 2019, Canadian Geotechnical Society.

Lo, S. R. \& Wardani, S. P. 2002. Strength and dilatancy of a silt stabilized by a cement and fly ash mixture. Canadian Geotechnical Journal 39(1):77-89.

Malandraki, V. \& Toll, D. 2000. Drained probing triaxial tests on a weakly bonded artificial soil. Géotechnique 50(2):141-151.

Malandraki, V. \& Toll, D. G. 2001. Triaxial Tests on Weakly Bonded Soil with Changes in Stress Path. Journal of Geotechnical and Geoenvironmental Engineering 127(3):282-291.

Miura, N., Horpibulsuk, S. \& Nagaraj, T. S. 2001. Engineering behaviour of cement stabilized clay at high water content. Soils and Foundations 41(5):33-45.

Rios, S., Fonseca, A. V. D. \& Baudet, B. A. 2012. Effect of the Porosity/Cement Ratio on the Compression of Cemented Soil. Journal of Geotechnical and Geoenvironmental Engineering 138(11):1422-1426.

Rotta, G. V., Consoli, N. C., Prietto, P. D. M., Coop, M. R. \& Graham, J. 2003. Isotropic yielding in an artificially cemented soil cured under stress. Géotechnique 53(5):493-501.

Santos, A. P. S. D., Consoli, N. C., Heineck, K. S. \& Coop, M. R. 2010. High-Pressure Isotropic Compression Tests on Fiber-Reinforced Cemented Sand. Journal of Geotechnical and Geoenvironmental Engineering 136(6):885-890.

Simms, P., \& Grabinsky, M. 2009. Direct measurement of matric suction in triaxial tests on early-age cemented paste backfill. Canadian Geotechnical Journal, 46(1),93-101.

Thompson, B. D., Grabinsky, M. W., Veenstra, R., \& Bawden, W. F. 2011. In situ pressures in cemented paste backfill - a review of fieldwork from three mines. In Proceedings of the 14th International Seminar on Paste and Thickened Tailings (pp. 491-503). Australian Centre for Geomechanics.

Xiao, H.-W. \& Lee, F.-H. 2014. An energy-based isotropic compression relation for cement-admixed soft clay. Géotechnique 64(5):412-418.

Xiao, H., Lee, F. H. \& Chin, K. G. 2014. Yielding of cement-treated marine clay. Soils and Foundations 54(3):488-501. 